\section{Benzodiazepine use and wine consumption in the French elderly}

Alcohol, especially wine, may be the most commonly used anxiolytic. France is a country which has among the highest per capita use of wine and of benzodiazepines $[1,2]$. It is not known whether these are used as a complement to one other, or as substitutes.

To explore this, we examined the relationship of current wine intake to benzodiazepine (BZD) use in a cohort of community residents, 65 years and older living in the area of Bordeaux, France, included in the Paquid program in $1989(n=3777)$ [3]. Usual daily intake of wine was estimated from a questionnaire on food habits. Daily wine consumption was divided into: (i) none, (ii) moderate: up to $0.251 \mathrm{day}^{-1}$ and (iii) heavy: more than $0.251 \mathrm{day}^{-1}$. Benzodiazepine use was recorded on adhoc questionnaires including visual control of patient pharmacies. Multivariate unconditional logistic regression was used to calculate the odds ration (ORs) and 95\% confidence intervals $(95 \% \mathrm{CIs})$ for BZD use and wine consumption, after adjustment for potential confounding variables (age, gender, living alone, depressive symptomatology evaluated by the Center for Epidemiological Studies-Depression (CES-D) scale, global cognitive decline defined as a Mini-Mental State Examination
(MMSE) score lower than 24, education level and subjective health assessment).

Table 1 shows the baseline characteristics of the 3767 persons (99.7\%) for whom wine consumption was available. Current use of benzodiazepines was inversely correlated to drinking patterns: $37.4 \%$ of non-drinkers used BZD, compared with $31.3 \%$ of moderate drinkers (unadjusted OR 0.76; 95\% CI 0.66, 0.88; adjusted OR $0.99 ; 95 \%$ CI $0.85,1.16$ ), and $19.3 \%$ of heavy drinkers (unadjusted OR $0.40 ; 95 \%$ CI 0.32, 0.50; adjusted OR $0.70 ; 95 \%$ CI $0.52,0.94$ ) (Table 2). This relationship was essentially unchanged during subsequent follow-up of the same population.

Table 2 Unadjusted and adjusted odds ratios (ORs) for benzodiazepine use dependent on wine consumption.

\begin{tabular}{|c|c|c|c|}
\hline & \multicolumn{3}{|c|}{ Wine consumption at baseline } \\
\hline & None & $\begin{array}{c}\text { Moderate } \\
\left(\leq 0.25 \text { lday }^{-1}\right)\end{array}$ & $\begin{array}{c}\text { Heavy } \\
\left(>0.25 \text { lday }^{-1}\right)\end{array}$ \\
\hline Unadjusted OR (95\% CI) & 1 & $0.76(0.66,0.88)$ & $0.40(0.32,0.50)$ \\
\hline Adjusted OR $\star(95 \%$ CI $)$ & 1 & $0.99(0.85,1.16)$ & $0.70(0.52,0.94)$ \\
\hline
\end{tabular}

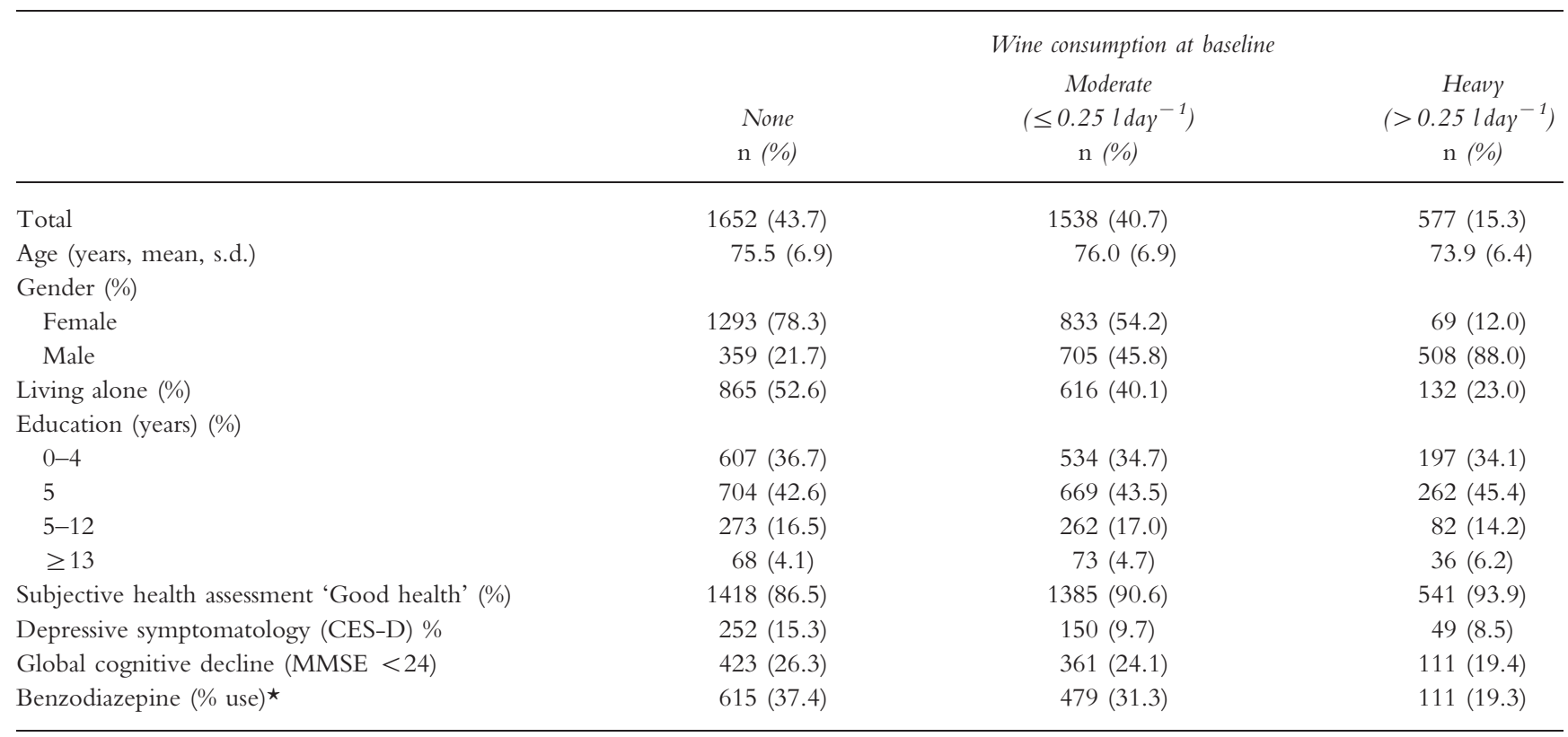

$\star$ Data are based on BZD use among 1643 non drinkers, 1528 moderate drinkers and 575 heavy drinkers. 
Heavy wine consumption $\left(>0.251 \mathrm{day}^{-1}\right)$ is associated, in the 65 years old and above population, with a lower use of benzodiazepines, contrary to the finding of Finnish doctors [4]. The direction of a possible causality is uncertain, and the relative health benefits between wine and benzodiazepines to treat anxiety could be a matter of debate [5].

\section{Rajaa Lagnaoui,' Nicholas Moore,' Jean François Dartigues, ${ }^{2}$ Annie Fourrier \& Bernard Bégaud'}

${ }^{1}$ Département de Pharmacologie, Université Victor Segalen, Bordeaux 2, Bordeaux and ${ }^{2}$ INSERM U.330, Université Victor Segalen, Bordeaux 2, Bordeaux, France

Received 2 October 2000, accepted 9 June 2001

Correspondence: Rajaa Lagnaoui, Département de Pharmacologie, Université Victor Segalen, Bordeaux2, 33076 Bordeaux cedex, France. Tel.: (+33) 557571560; Fax: (+33) 556245889 ;

E-mail: raja.lagnaoui@pharmaco.u-bordeaux2.fr

\section{References}

1 Guignon N, Mormiche P, Sermet C. Epidemiological aspects of chronic use of psychotropic drugs. In La Consommation Régulière de Psychotropes. Paris April, 1994, National Institute of Statistics and Economic Studies, INSEE Premiere no. 310 (in French) (http://www.INSEE.fr).

2 Peele S. Utilizing culture and behaviour in epidemiological models of alcohol consumption and consequences for Western Nations. Alcohol Alcoholism 1997; 32: 51-64.

3 Dartigues JF, Gagnon M, Michel P. Le programme de recherche PAQUID sur l'épidémiologie de la démence. Méthodologie et résultats initiaux. Rev Neurol 1991; 147: 225-230.

4 Juntunen J, Asp S, Olkinuora M, Aarimaa M, Strid L, Kauttu K. Doctor's drinking habits and consumption of alcohol. Br Med J 1988; 297: 951-954.

5 Shorr RI, Robin DW. Rational use of benzodiazepines in the elderly. Drugs Aging 1994; 4: 9-20.

\section{Possible interaction between gliclazide, fluconazole and sulfamethoxazole resulting in severe hypoglycaemia}

Keywords: cytochrome P450, drug interactions, hypoglycaemia, metabolism, sulphonylureas

Hypoglycaemia in acquired immunodeficiency syndrome (AIDS) was mostly encountered when pentamidine was used to treat Pneumocystis carinii pneumonia [1]. We report the case of an HIV-infected patient with diabetes mellitus who developed hypoglycaemia when treated with gliclazide, sulfamethoxazole and fluconazole. To our knowledge, hypoglycaemia had never been linked to the interaction between these drugs.

\section{Case report}

A 56-year-old HIV-infected patient was admitted to hospital because of weakness and aggressive behaviour. $\mathrm{He}$ was known to have diabetes mellitus and had been treated with gliclazide $\left(160 \mathrm{mgday}^{-1}\right)$ for 2 years without previous evidence of hypoglycaemia. AIDS had been diagnosed 2 months earlier because of oral candidosis treated with fluconazole $\left(50 \mathrm{mg} \mathrm{day}^{-1}\right)$ for 2 weeks. CD4 lymphocyte count was $42 / \mathrm{mm}^{3}$ and plasma HIV viral load was 12700 RNA copies $\mathrm{ml}^{-1}$. Prophylactic treatment with sulfamethoxazole (400 $\mathrm{mg} \mathrm{day}^{-1}$ ) and trimethoprim $\left(80 \mathrm{mg} \mathrm{day}^{-1}\right)$ was started. Antiretroviral treatment was refused. Two months later, 1 week after reintroduction of fluconazole at a higher dose $\left(200 \mathrm{mg} \mathrm{day}^{-1}\right)$, he presented with weakness and disturbed behaviour. On examination, he was afebrile and there was no sensorimotor deficiency but there was hyporeflexia in his legs. A computed tomographic scan of the head was normal. Haemoglobin level and CD4 lymphocyte count were $10 \mathrm{~g} \mathrm{dl}^{-1}$ and $50 / \mathrm{mm}^{3}$ respectively. All other laboratory tests were normal, except for a blood glucose concentration of $2.2 \mathrm{mmoll}^{-1}$. Gliclazide was stopped. Two days later, the patient had a brief loss of consciousness while he was driving his car. His condition then improved. Neurologic symptoms did not recur during 3 month follow-up without retreatment with gliclazide.

Hypoglycaemia occurring in diabetic patients treated with sulphonylurea drugs has been well documented. In a multicentre study of hypoglycaemia induced by sulphonylureas between 1985 and 1990, gliclazide was implicated in 55\% (46/98) of cases and the main cause was drug interactions, suspected in nearly $50 \%$ of cases [2]. The most frequent drug interaction involved miconazole (9/49) that inhibits, like fluconazole, cytochrome P4502C9 (CYP2C9) [3].

Data from studies with rat livers suggest that gliclazide is mainly metabolized by the same cytochrome (CYP2C9) as tolbutamide and to a lesser extent by CYP2D6 [4, 5]. Our patient received a high dose of fluconazole and gliclazide. Fluconazole might have strongly inhibited CYP2C9 and increased the serum concentration of gliclazide. Sulfamethoxazole also inhibits CYP2C9 and could have contributed to hypoglycaemia [2, 3].

The relapse of neurologic symptoms 2 days after discontinuation of gliclazide was compatible with an increase in its half-life (normal half-life $=10-14 \mathrm{~h}$ ) as it was reported that tolbutamide half-life was enhanced three fold in patient receiving CYP2C9 inhibitor [6]. 
We believe fluconazole coadministered with sulfamethoxazole resulted in inhibition of gliclazide metabolism leading to severe hypoglycaemia. Physicians should consider this potential interaction in the management of HIV-infected patients in whom highly active antiretroviral therapy frequently triggers diabetes mellitus.

\section{S. Abad,' L. Moachon, ${ }^{2}$ P. Blanche, ' F. Bavoux, ${ }^{2}$ D. Sicard' \& D. Salmon-Céron' \\ ${ }^{1}$ Service de Médecine Interne 2 and ${ }^{2}$ Service de Pharmacologie- \\ Pharmacovigilance, Hôpital Cochin - St Vincent de Paul, Université René Descartes, 27 rue du faubourg St Jacques, 75679 Paris, Cedex 14, France.}

Received 2 October 2000, accepted 9 June 2001

Correspondence: Dr Sébastien Abad. Service de Médecine Interne 2, Hôpital Cochin - St Vincent de Paul, Université René Descartes, 27 rue du faubourg St Jacques, 75679 Paris, Cedex 14, France. Tel.: 331584121 13; Fax: 331584120 80; E-mail: sebastien.abad@, cch.ap-hop-paris.fr

\section{References}

1 O'Brien JG, Dong BJ, Coleman RL, Gee L, Balano KB. A 5-year retrospective review of adverse drug reactions and their risk factors in human immunodeficiency virus-infected patients who were receiving intravenous pentamidine therapy for Pneumocystis carinii pneumonia. Clin Infect Dis 1997; 24: 854-859.

2 Girardin E, Vial T, Pham E, Evreux JC. Hypoglycémies induites par les sulfamides hypoglycémiants. Recensement par les centres Régionaux de pharmacovigilance français de. 1985 à 1990. Ann Med Interne 1992; 143: 11-17.

3 Venkatakrishnan K, Von Moltke LL, Greenblatt DJ. Effects of the antifungal agents on oxidative drug metabolism: clinical relevance. Clin Pharmacokin 2000; 38: 111-180.

4 Rieutord A, Stuppans I, Shenfield GM, Gross AS. Glicazide hydroxylation by rat liver microsomes. Xenobiotica 1995; 25: $1345-1354$

5 Komatsu K, Ito K, Nakajima Y, et al. Prediction of in vivo drug-drug interactions between tolbutamide and various sulfonamides in humans based on in vitro experiments. Drug Metab Dispos 2000; 28: 475-484.

6 Pond SM, Birkett DJ, Wade DM. Mechanism of inhibition of tolbutamide metabolism. Phenylbutazone, oxyphenbutazone, sulfaphenazole. Clin Pharmacol Ther 1977; 22: 573-579.

\section{Systemic bioavailability of fluticasone proprionate}

We read the recent article of Daley-Yates \& Baker [1] regarding the systemic bioavailability of four consecutive $800 \mu \mathrm{g}$ doses intranasal fluticasone aqueous spray given over $24 \mathrm{~h}$ in healthy volunteers. The pharmacokinetic data presented suggest a low degree of systemic exposure in terms of the plasma fluticasone concentration as compared with historical data from a reference intravenous dose.
They also postulate in the discussion that the systemic bioavailability of fluticasone is much lower than other intranasal aqueous corticosteroid formulations such as budesonide or triamcinolone acetonide when given via the intranasal route, because of differences in their oral bioavailability.

The lower plasma concentrations of fluticasone as compared with budesonide or triamcinolone are more likely to be due to differences in lipophilicity and volume of distribution, in that highly lipophilic drugs such as fluticasone preferentially distribute into the systemic fat tissue reservoir, resulting in a large volume of distribution and a relatively lower concentration in the water soluble blood compartment at steady-state [2]. Consequently, measuring only the low concentration of fluticasone in the plasma compartment will greatly underestimate the total systemic exposure, and this is borne out by several studies which have evaluated systemic adverse effects of intranasal fluticasone given at much lower daily doses than were evaluated by Daley-Yates \& Baker.

In a study of healthy volunteers significant HPA-axis suppression was shown in terms of a $43 \%$ reduction of overnight urinary cortisol excretion with intranasal fluticasone spray $200 \mu \mathrm{g}$ daily compared with placebo, whereas the effect of triamcinolone spray $220 \mu \mathrm{g}$ daily was not significant (23\% reduction) [3]. In another study in patients with allergic rhinitis, intranasal triamcinolone spray $220 \mu \mathrm{g}$ daily or budesonide spray $200 \mu \mathrm{g}$ daily exhibited no significant effects on $24 \mathrm{~h}$ or fractionated cortisol profiles measured in blood or urine [4]. Furthermore in healthy volunteers receiving intranasal fluticasone spray $200 \mu \mathrm{g}$ daily for 1 week followed by $400 \mu \mathrm{g}$ daily for a second week, there was a $37 \%$ fall in $0800 \mathrm{~h}$ serum cortisol, a $24 \%$ fall in $24 \mathrm{~h}$ urinary cortisol, a $45 \%$ fall in serum osteocalcin as well as a $28 \%$ fall in peripheral blood lymphocytes glucocorticoid receptor mRNA expression, all of which were highly significant effects $(P<0.001)$ [5]. Moreover after stopping fluticasone for one week there was persistent suppression of peripheral lymphocyte glucocorticoid receptor mRNA expression (33\% reduction) which would suggest prolonged systemic retention of fluticasone with sustained release from the systemic tissue reservoir into the blood compartment. This would be consistent with its large volume of distribution due to its lipophilicity, with much higher tissue than plasma concentrations. In the same study [5], twice the daily dosage of intranasal budesonide was found to exhibit significant effects of comparable magnitude on the same systemic bioactivity markers, although there was no persistent suppression of mRNA after one week of washout. In patients with allergic rhinitis intranasal fluticasone spray $200 \mu \mathrm{g}$ daily produced a $38 \%$ fall in peripheral blood eosinophil count and a $13 \%$ fall in $24 \mathrm{~h}$ urinary cortisol excretion, although only the former achieved statistical significance [6]. 
An apparent lack of HPA-axis suppression with $800 \mu \mathrm{g}$ daily of intranasal fluticasone spray [7] using a $250 \mu \mathrm{g}$ ACTH stimulation test may be explained by the known insensitivity of this test, as $250 \mu \mathrm{g}$ represents a supraphysiological dose of ACTH, with much lower doses of ACTH (i.e. 0.5-1.0 $\mu \mathrm{g}$ ) being as effective in producing a stimulated cortisol reponse [8].

It is therefore more clinically relevant to evaluate sensitive tests of potential systemic bioactivity in order to assess the true systemic exposure of intranasal fluticasone, rather than measuring the systemic bioavailability in terms of its plasma concentration. Indeed, it is the presence or absence of systemic adverse effects which matters more to the prescribing clinician, in terms of evaluating the benefit/risk ratio of intranasal corticosteroid formulations.

\section{B. J. Lipworth}

Asthma and Allergy Research Group, Department of Clinical Pharmacology and Therapeutics, Ninewells Hospital and Medical School, University of Dundee, Dundee Scotland DD1 $9 S Y$

Received 2 October 2000, accepted 9 June 2001

Correspondence: Professor B. J. Lipworth, Asthma and Allergy Research Group, Department of Clinical Pharmacology and Therapeutics, Ninewells Hospital and Medical School, University of Dundee, Dundee Scotland DD1 9SY. Tel.: 01382632983 (direct), 01382632180 (secretary); Fax: 01382632983 (direct), 01382644972 (secretary); E-mail: b.j.lipworth@dundee.ac.uk

\section{References}

1 Daley-Yates PT, Baker RC. Systemic bioavailability of fluticasone propionate administered as nasal drops and aqueous nasal spray formulations. Br J Clin Pharmacol 2001; 51: 103-105.

2 Lipworth BJ, Jackson C. Safety of inhaled and intranasal corticosteroids: lessons for the new millennium. Drug Safety 2000; 23: 11-33.

3 Wilson AM, McFarlane LC, Lipworth BJ. Effects of repeated once daily dosing with three intranasal corticosteroids on basal and dynamic measures of HPA-axis activity. J Allergy Clin Immunol 1998; 101: 470-474.

4 Wilson AM, McFarlane LC, Lipworth BJ. Effects of intranasal corticosteroid on adrenal, bone and blood markers of systemic activity in allergic rhinitis. J Allergy Clin Immunol 1998; 102: 598-604.

5 Knutsson PU, Stierna P, Marcus C, Carlstedt-Duke J, Carlstrom K, Bronnegard M. Effects of intranasal glucocorticoids on endogenous glucocorticoid peripheral and central function. J Endocrinol 1995; 144: 301-310.

6 Foresi A, Pelucchi A, Gherson G, Mastropasqua B, Chiapparino A, Testi R. Once daily intranasal fluticasone propionate $(200 \mu \mathrm{g})$ reduces nasal symptoms and inflamation but also attenuates the increase in bronchial responsiveness during the pollen season in allergic rhinitis. J Allergy Clin Immunol 1996; 98: 274-282.
7 Vargas R, Dockhorn RJ, Findlay SR. Effect of fluticasone propionate aqueous nasal spray versus oral prednisone on hypothalmic-pituitary-adrenal-axis. J Allergy Clin Immunol 1998; 102: 191-197.

8 Lipworth BJ, Seckl JL. Measures for detecting systemic bioactivity with inhaled and intranasal orticosteroids. Thorax 1997; 52: 476-482.

\section{A reply:}

Professor Lipworth suggests that the tissue distribution of lipophilic corticosteroids is a more important factor than bioavailability in determining systemic effects. The steadystate volume of distribution, a measure of the partitioning of drugs between plasma and tissues, is high for all intranasal corticosteroids. The values range from 1031 [1] for triamcinolone acetonide to 4241 for beclomethasone17-monopropionate (the active metabolite of (beclomethasone dipropionate) [2]. All these values are large compared with the volume of plasma (31) so the majority of the absorbed dose will be distributed to the tissue (97-99\%) for all intranasal corticosteroids. For example, triamcinolone acetonide has a smaller volume of distribution than fluticasone propionate (3181), however, the plasma and tissue exposures are estimated to be greater than for fluticasone propionate because of the higher bioavailability of triamcinolone acetonide. For triamcinolone acetonide (bioavailability 46\%, dose $220 \mu \mathrm{g}$ ) $101 \mu \mathrm{g}$ will be absorbed following each dose and $97 \%$ of this $(98 \mu \mathrm{g})$ will distribute to the tissues. In contrast, for fluticasone propionate (bioavailability $0.5 \%$, dose $200 \mu \mathrm{g}$ ) $1 \mu \mathrm{g}$ will be absorbed following each dose and although $99 \%$ of this will distribute to the tissues this amounts to $<1 \mu \mathrm{g}$. This higher exposure to triamcinolone acetonide, in both tissues and plasma, persists for approximately $20 \mathrm{~h}$ during a dose interval at steady-state despite its shorter elimination half-life (Figure 1). The relationship between tissue and plasma distribution for other intranasal corticosteroids is also shown in Figure 1. The conclusions from this analysis are firstly that for all intranasal corticosteroids most of the drug is found in the tissues during multiple dosing. Secondly, the bioavailability rather than the volume of distribution is clearly the most important factor in determining tissue exposure. Finally, even when allowance is made of the lower potency of triamcinolone acetonide compared with fluticasone propionate lower systemic effects are still predicted for fluticasone propionate [3].

The low absolute bioavailability of intranasal fluticasone propionate is due to low absorption from both the nose and the gut and its measurement is not influenced by the volume of distribution. Fluticasone propionate is administered as an aqueous suspension and its absorption 


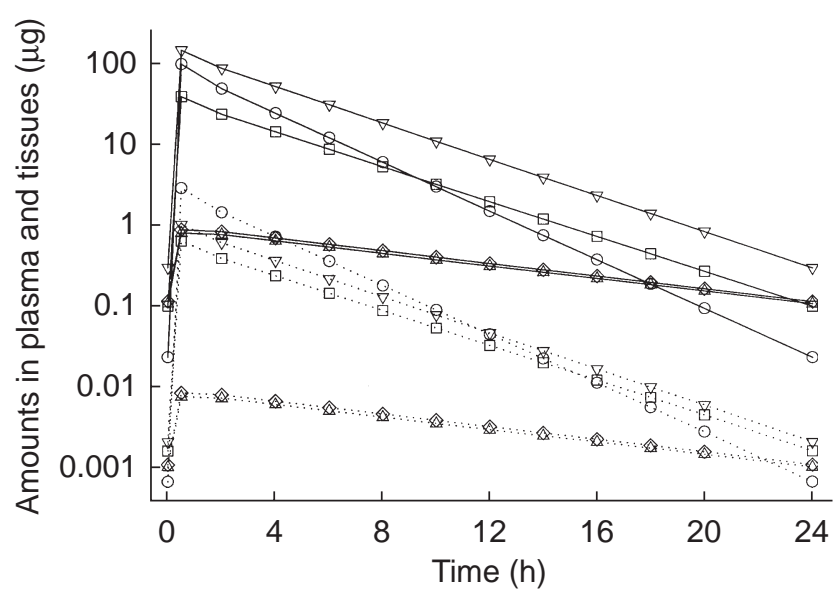

Figure 1 Calculated amounts of corticosteroid in plasma (...) and tissues (-) at steady-state for once daily dosing of intranasal corticosteroid aqueous nasal spray formulations at their clinical doses (triamcinolone acetonide $220 \mu \mathrm{g} \bigcirc$, beclomethasone dipropionate $336 \mu \mathrm{g} \nabla$, budesonide $128 \mu \mathrm{g} \square$, mometasone furotae $200 \mu \mathrm{g} \diamond$ and fluticasone propionate $200 \mu \mathrm{g} \triangle$ ). Values are based on published values of volume of distribution at steady-state, systemic bioavailability and clearance. (source [3]).

directly in the nose appears to be limited by dissolution [4]. The aqueous solubility of fluticasone propionate is very low, therefore most of the drug is cleared by the nasal cilia and swallowed before dissolution occurs. The swallowed dose is subject to almost complete first pass metabolism resulting in negligible oral bioavailability [5], whereas for intranasal corticosteroids with higher systemic absorption oral bioavailablity provides a major contribution to systemic exposure and higher aqueous solubility results in greater nasal absorption [3].

Lipworth cites a study by Wilson et al. [6] as evidence that $200 \mu \mathrm{g} \mathrm{day}^{-1}$ intranasal fluticasone propionate has significant systemic effects. However, the reference does not support this as overnight urinary cortisol excretion corrected for creatinine, morning serum cortisol and ACTH stimulation tests were not different from placebo. There were changes in overnight urinary cortisol excretion ( $9.5 \mathrm{~h}$ collection period) uncorrected for creatinine but there is no justification for using this parameter and ignoring the others. There are a number of reasons why the reported $43 \%$ reduction in overnight urinary cortsiol uncorrected for creatinine is not a robust result and a detailed account of the perceived flaws in that study has been published in a letter to another journal [7]. As a follow-up to this correspondence the author replicated the Wilson et al. study [6] using LC-MS/MS assay methodology and failed to show any significant change in overnight cortisol excretion following repeat daily dosing with
$200 \mu \mathrm{g}$ intranasal fluticasone propionate [8]. Furthermore, in a double blind, cross-over placebo controlled study [9], using a robust measurement of HPA axis effects $(24 \mathrm{~h}$ serum cortisol AUC), repeat daily dosing with $200 \mu \mathrm{g}$ intranasal fluticasone propionate produced no change relative to placebo (ratio $1.01,90 \%$ CI $0.90,1.14$ ). Other studies have also failed to show significant changes in cortisol using much higher doses than those used by Wilson et al. [10, 11].

An examination of the literature in this area illustrates a lack of robustness in the methodology where urinary cortisol has been used to assess systemic exposure to corticosteroids. There are a number of possible explanations for this including: lack of assay sensitivity, crossreactivity with corticosteroids and their metabolites, circadian influences on the choice of sampling period and nonlinear responses to exogenous corticosteroids exposure [12].

The other study Lipworth uses to support his arguments [13] was not placebo controlled so changes in cortisol excretion and the other parameters measured over time are difficult to interpret, but nevertheless the authors concluded that 'according to serum and urinary cortisol levels the hypothalamic-pituitary-adrenal function remained intact'. The biochemical and cellular changes reported in the study cannot be interpreted as an indicative of systemic exposure to corticosteroids as they could arise following topical exposure and subsequent cell migration. In the context of long-term safety a more significant observation is that long-term exposure to intranasal corticosteroids with high systemic exposure such as BDP can have effects on growth velocity in children [14]. However, this has not been reported for corticosteroids with low systemic bioavailability such fluticasone propionate and mometasone furoate [10, 15].

Knowledge of the systemic bioavailability and potency of intranasal corticosteroids is a more logical basis for predicting relative systemic effects. Studies relying on HPA axis effects alone are not useful in this regard, not only due to concerns surrounding the methodology [16] but also because no link has been established between these measurements and the long-term safety of inhaled corticosteroids. Against this background it is difficult to see the value of such studies in guiding the prescribing physician. However, based on systemic bioavailability and potency data, relevant HPA axis effects are not likely when intranasal corticosteroids are administered at their recommended doses [3].

\section{Peter T. Daley-Yates}

GlaxoSmithKline, Greenford Road, Greenford, Middlesex UB6 OHE 


\section{References}

1 Derendorf H, Hochhaus G, Rohatagi S. Pharmacokinetics of triamcinolone acetonide after intravenous, oral and inhaled administration. J Clin Pharmacol 1995; 35 : 302-305.

2 Daley-Yates PT, Price AC, Sisson JR, Pereira A, Dallow N. Beclomethasone dipropionate: absolute bioavailability, pharmacokinetics and metabolism following intravenous, oral, intranasal and inhaled administration in man. $\mathrm{Br} \mathrm{J}$ Clin Pharmacol 2001; 51: 400-409.

3 Daley-Yates PT, Richard DH. Pharmacokinetics and pharmacodynamic relationships for intranasal corticosteroids (INCS). J Allergy Clin Immunol 2001; 107: S313.

4 Daley-Yates PT, Baker RC. Systemic bioavailability of fluticasone propionate administered as nasal drops and the aqueous nasal spray formulations. Br J Clin Pharmacol 2001; 51: 103-105.

5 Falcoz C, Oliver R, McDowall J, Ventresca GP, Bye A, Daley-Yates PT. Bioavailability of orally administed micronised fluticasone propioante. Clin Pharmacokinet 2000; 39(Suppl 1): 9-15.

6 Wilson AM, McFarlane LC, Lipworth BJ. Effects of repeated once daily dosing with three intranasal corticosteroids on basal and dynamic measures of HPA-axis activity. J Allergy Clin Immunol 1998; 101: 470-474.

7 Bachert C. Letters to the ed. J Allergy Clin Immunol 1999; 103: 355.

8 Bachert C, Lukart K, Lange B, Baker RC. Basal and dynamic measures of hypothalamic-pituitary-adrenal axis activity - the effects of intranasal fluticasone propionate, triamcinolone acetonide and placebo. J Allergy Clin Immunol 2001; 107: S156.
9 Price AC, Daley-Yates PT, Wright AM, Callejas S. Negligible absolute bioavailability and no HPA-axis effects after multiple $200 \mu \mathrm{g}$ daily doses of Fluticasone propionate (FP) administered from the aqueous nasal spray (FPANS). Eur Resp J 2000; 16: 279s.

10 Daley-Yates PT, Kunka RL, Shen YY, Andrews SM, Callejas S, Ng C. The relative systemic exposure to fluticasone propionate (FP) and mometasone furoate (MF) administered as aqueous nasal sprays in healthy subjects. J Allergy Clin Immunol 2000; 105: S201.

11 McDowell JE, Mackie AE, Ventresca GP, Bye A.

Pharmacokinetics and bioavailability of intranasal fluticasone in humans. Clin Drug Invest 1997; 1: 44-52.

12 Pierre LN, Daley-Yates PT. Cortisol measurements in healty subjects do not reliably quantify the systemic exposure to exogenous corticosteroids. Eur Resp J 2000; 16: 280 s.

13 Knutsson PU, Stierna P, Marcus C, Carlstedt-Duke J, Carlstrom K, Bronnegard M. Effects of intranasal glucocorticosteroids on endogenous glucocortocoid peripheral and central function. J Endocrinol 1995; 144: 301-310.

14 Skoner DP, Rachelefsky GS, Meltzer EO, et al. Detection of Growth suppression in children during treatment with intranasal beclomethasone dipropionate. Pediatrics 2000; 105(2): E23.

15 Schenkel EJ, Skoner DP, Bronsky EA, et al. Absence of growth retardation in children with perennial allergic rhinitis after one year of treatment with mometasone furoate. Pediatrics 2000; 105: E22.

16 Pierre LN, Fink RS, Daley-Yates PT, Richards DH, Honour JW. Observed cortisol suppression following inhaled corticosteroids is influenced by the analytical method. Am J Resp Crit Care Med 2001; 163: A518. 